\title{
Tomato Leaf Curl Virus of Tomato: Scenarios and Confronts
}

Arpitha Shankar

Department of Agriculture Biotechnology, Sardar Vallabhbhai Patel University of Agriculture \&amp;amp; Technology, Meerut-250 110, Uttar Pradesh, India

\begin{abstract}
Tomato leaf curl disease (TLCD) is the most common viral disease in the tomato plant. It is caused by begomoviruses, which are viruses that cause plant development to be slowed. Many of the traditional disease management methods are still in use. They are, however, ineffective and out of date. Modern biotechnology is being used to detect illness in tomato plants as early as possible, thus reducing damage to the plants. Through genetic engineering, the spread of viruses may be controlled or prevented entirely. Here reviewed many methods for decreasing or eliminating the viral influence on crop growth through biotechnology and genomics. We also investigated the possibility of genetic engineering to reduce or remove the virus TLCD impact on tomato crop development.
\end{abstract}

Keywords: Tomato; Begomovirus; Leaf Curl; Strain

INTRODUCTION:

Tomatoes are a very significant vegetable crops that have gained immense popularity over the last century and are now grown nearly in every country all over the world [1]. Due to the economic importance of tomato and its role as a model for its fleshy fruit development, secondary metabolism, disease resistance, domestication, and evolution, significant efforts have been made to develop genetic and genomic resources for this species. As a result, tomato was chosen as the model genome for the economically important Solanaceae family (e.g., potato, pepper, and eggplant). The wild cherry tomato (often designated as $S$.

lycopersicum var. cerasiforme) is the most likely progenitor of cultivated tomatoes, due to its greater distribution and possibly more recent dispersal into Mexico, Colombia and Bolivia

[2]. Wild tomato cousins are indigenous to western South America, ranging from central Ecuador to northern Chile and the Galápagos Islands, along the coast and in the high Andes. Without a doubt, the Andean topography, the diversity of biological niches, and the range of temperatures all contributed to the diversity of wild tomato species [3].

Mineral synthesis in tomatoes is reliant upon amount and kind of mineral involved from development media and soil. Inadequate amounts of supplements availability show insufficiency indications and influence the creation and nature of tomato [4]. Sugars, dietary 
filaments, carotenoids what's more, cell reinforcement shade named lycopene gives the red shading to tomatoes are available, which helps in the concealment of cancer-causing substances and considered valuable for the sound health of individuals [5]. Shading is vital to pass judgment on the nature of the product quality, and the red shade of tomato is a direct result of the creation of a cell reinforcement compound named lycopene.Cell reinforcement movement and the absolute number of carotenes in tomatoes are reliant upon age and assortment [6]. Tomato plants are susceptible to a variety of viral infections, the most severe of which is tomato leaf curl virus. In India, tomato production is severely constrained by the disease tomato leaf curl virus, which occurs on a regular basis (ToLCVD). [7] Numerous tomato leaf curl virus (ToLCV) isolates cause ToLCVD, the most severe strain being the tomato leaf curl new Delhi virus in north India [8].

In India, the tomato leaf curl viral disease has had a significant negative impact on tomato agriculture and output $[9,10,7]$. The high frequency of tomato leaf curl viral disease has a severe impact on tomato agriculture, particularly in the fall in north India and throughout the summer season in south India, with losses frequently exceeding 90\%.[11]. When plants are infected within the first 20 days of sowing, their growth is significantly slowed and they produce a small number of leaves and fruits, resulting in up to 92.3 percent loss [11]. Temperature appears to have an effect on virus transmission, with an optimal range of $33-39^{\circ} \mathrm{C}$. In tomato plants, the virus remained dormant for only eight days during the summer and 90 days during the winter [11]. The increased incidence of leaf curl disease in autumn is related to the effect of temperature on viral transmission [13]. Tomato leaf curl disease (ToLCD), which is caused by the virus family Tomato leaf curl virus, is one of the most destructive tomato diseases, especially in tropical regions [14]. Infected vulnerable plants frequently exhibit severe leaf bending, leaf shrinkage, and stunted growth. This disease is believed to be caused by many species of Begomovirus (Geminiviridae family), which is transmitted by Whiteflies (Genn Bemisia Tabaci.). It has a mono-/bi-partite genome and, in some instances, requires the presence of a beta satellite molecule to initiate infection or exacerbate disease manifestations. In northern and western India, bipartite begomoviruses associated with ToLCD have been identified [15]. Among these numerous begomoviruses, the Tomato leaf curl New Delhi virus (ToLCNDV), discovered in India's New Delhi region, is extremely widespread and infects a variety of other crops. The severity of symptoms varies significantly, ranging from very minor to severe symptoms and plant death [16]. Begomoviruses and whiteflies share an intricate relationship. B. tabaci spreads TYLCV via 
circulative transmission. TYLCV and other similar viruses have a number of detrimental effects on insect pathogens: they reduce the lifespan and fertility of B. tabaci and are occasionally transmitted transovarially; they alter the whitefly transcriptome, increasing the expression of genes involved in the whitefly immune response [17].

To understand and reduce the effect of Tomato leaf curl disease caused by virus TYLCV several attempts are being made. First the biotechnology of the viral gene is known and its expression is understood along with the genomic analysis of the plant and later genetic engineering methods were employed to carefully study the viral and plant genome[18]. Numerous crops have been evaluated using morphological and biochemical characteristics [2 ,19].Exploiting such characteristics increases our understanding of accessible genetic diversity, which may facilitate their use in breeding for enhanced regional adaptation to biotic and abiotic stressors, as well as short- and long-term breeding endeavors.

In this article, we have reviewed information on ToLCV occurrence, pathogen variability, biotechnology of the virus, genomics and genetic engineering approaches to reduce the effect of virus on the cultivar development; and analyzing future prospects of ToLCV resistance breeding in tomato [20].

Variation and diversification in tomato yellow leaf curl virus (TYLCV) affecting tomato because it has been discovered in species from 16 plant families, the tomato yellow leaf curl virus (TYLCV) is the most available of the begomoviruses. Multiple TYLCV resistance sources have been discovered and are being utilized to create resistant tomato cultivars. Despite field-based resistance, TYLCV has risen to become the most common and damaging virus in tomato and pepper plants [21]. The introduction of viral resistance genes from wild relatives, such as Ty-1 to Ty-6, into cultivated tomato varieties, has improved viral resistance, but it didn't reach 100 percent. In conjunction with TYLCV's high evolutionary potential, it is possible that resistance-driven selection pressure had a role in the virus's emergence [22]. It is necessary to make more cohesive improvements in TYLCV regulation in order to compensate for host resistance. Plant viruses co-evolve with their hosts and vectors to become more effective. The virus must thus retain its genomic structure and protein activity in order to transmit and replicate in vectors while still being motile. We developed a model for begomovirus evolution based on a typical Begomovirus master/founder genome and tested it in the laboratory [23].

The results of previous evolutionarily based studies have shown that betasatellites are divided into two groups: those that originate in one host and those that originate in another. 
As a result of our results, the coadaptation of betasatellites with the help of begomoviruses is supported [24]. Because of the virus's repeated reproduction cycle in a host plant, selection may result in the virus becoming more adaptable to the host plant. The trans-replication of betasatellites by different begomoviruses may also contribute to genomic diversity by gaining homologous iteron-like patterns like human genome [25].

These instances demonstrate the importance and usefulness of favourable modifications in the plant viral genome, which may be used to explain the resistant pandemic. To create more effective control methods in agricultural areas, it is necessary to understand how begomoviral populations evolve [26]. It is reasonable to suppose that many viral determinants in begomoviruses are unknown because of the abundance of these changes. Greater efficiency in genome engineering methods will result in the discovery of new viral functions [27]. Future studies should concentrate on multidisciplinary methods such as host-dependent and vector/human-mediated dispersal-based evolution to understand BGVs and their expanding virosphere [28].

\section{TYLCV INCIDENCE AND OUTSPREAD:}

TyLCV was first reported in the Israeli Jordan Valley in 1930s [29, 30]and from India in the late 1940s. [31] first isolated and described TyLCV infection in tomatoes. Since then, a number of tomatoes infect Begomovirus has been explained. More than 60 species and hundreds of strains and isolates have been reported from various regions of the world $[31,32]$.The emergence of TYLCV and its spread throughout the world has been very fast [33]. In the early 1960s, this disease was reported from the Middle East; In the middle and late 1970s from Jordan and Lebanon [34, 35].

This disease still spreads to new areas, with a recent outbreak in California [36] and Hawaii [37] in the US, China [38] and Trinidad \& Tobago [39].

\section{SYMPTOMOLOGY}

It was proven that TOLCV exhibition disease symptoms similar to symptoms caused by Yellow Tomato Leaf Curl Virus (TYLCV). [40] mentioned that the symptoms in tomato plants begin in 2-3 weeks after being exposed to viruliferous white fly. Symptoms begin with small yellowing on margin leaflets in apical leaves and curved leaflets 
and above and bring up the next stage. After 30 days top leaves curling, cupping and yellowing occurs along with arresting plant growth, flowers and fruits are detached. [37] proves that characteristics symptoms shown by this disease include leaf lamina change yellow, curved leaves up, distortion leaves, reduce internships, new sizes appear leaf reduced, wrinkle facade inhibits growth. Whiteflies harboring viruses can infect wide ranging plants and Weeds like eggplant, potatoes, peppers, and beans. Infected plants look as if they are healthy but finally developing symptoms that lead to big economic losses. [42] illustrated that distinguishing symptoms are exhibited by infected vulnerable plants include curly leaves, shrinking leaves occur and reduce plant growth. They report causal agent of this disease is a genus member Begomovirus, and Whitefly is considered a vector and helps in transmission. [43] are provoked that TLCV can show different symptoms in tomatoes. Nonetheless can produce infections in the wild and cultivated species without showing symptoms, though at both cases host will act as a reservoir for viruses. Therefore, Whiteflies are able to obtain and transmit viruses from non-symptomatic infected plants regardless of TLCV are less in encouraging disease symptom.[44] explain that symptoms of characteristics shown by TylCV included curling of leaflet margins up, reduce leaflets area, teens leaves turn yellow, growth is hampered and termination of flower is seen.

\section{MANAGEMENT OF TOLCV :}

Through different strategies, TLCV can be managed [45] with slight modifications in techniques. There are several methods in conventional breeding where plant protection is less achieved which include like soil sterilization, crop rotation, grafting, vector management etc. Although these methods are well practiced but the molecular analysis and genetic manipulations have gained major importance in the present era to reduce the pest incidences and with less damage to the crop. In our review concentration was given to three main techniques to understand and to reduce the effect of TyLCV on plants.

\section{Biotechnology for tomato leaf curl virus:}

New methods and protocols have been published to understand the complete biology of the TOLCV virus and to reduce the incidence of the virus on the plant. A new method in biotechnology is studied and understood in our review in which the use of LAMP and PCR amplification to reduce the transmission of the virus [46]. Viruses are collected from the 
symptomatic plants grown under controlled conditions. These viruses are not only transmitted by vectors (white flies) but also through the contaminated seeds. These methods were proven beneficial because they detect the virus at the very young seedling stage before the incidence of disease in the plants [47]. TOLCV is a Gemini virus belonging to Begomovirus family which contain (total MW 980,000 covalently closed genomic circular ssDNA [48]. The required primers were deisgned to detect the effect of C1RAP gene in the symptomatic plants so that proper management facilities can be followed [49].

Through its uniqueness this method has provided the world with a powerful diagnostic tool and this gained much importance in the recent years in detecting the virus before the development of the symptoms. With the help of designed primers and optimized temperatures the samples were evaluated targeting C1RAP gene [50].

The PCR amplification is also considered an important step to identify the target gene[51]. DNA markers are designed using the resulting sequence from C1RAP genes only with shorter target areas taken from gene with amplicon size of 200bp [52].

All the samples were similar to that of the ladder which confirms the presence of the target gene and eventually virus incidence in the plants. Of all the samples selected for the detection of the presence of the virus, The samples were processed using PCR and LAMP analysis to investigate the early detection of the disease. Specific markers C1RAPG were designed and applied for detecting TOLCV in the leaves of tomato [53].

The Tolcv virus can not only be transmitted by whiteflies but it can also be transmitted from soil and seeds , the virus transmission acquisition period is $15-20$ mins and latent period is nearly about $48 \mathrm{hrs}$. Because of the time gap for the disease spread the plant can be saved by early necessary treatments [54]. LAMP is a powerful tool along with PCR the detection of the virus is made possible. Both these methods were proven to be very advantageous compared to conventional methods. These methods are highly efficient and advisable because LAMP and PCR identified the presence of the disease in the seedling at the very early stages, which is quiet beneficial. Also, the presence of the virus in soil and seeds is also checked simultaneously to check any further spread of the disease [55]. Altogether the biotechnology of the tomato leaf curl virus is understood by identifying the gene that is very important and responsible for replicationi.e., C1RAP gene. The influencing and identified gene C1RAP presence was confirmed and the disease incidence is detected at the early stages before the 
symptoms are fully expressed. In this case, the evidence on the presence of infected plants was strengthened before the expression of symptoms.

\section{Genomics of ToLCV:}

Gemini viruses are small particles usually found in pairs , they are called twin viruses and they do not need any helper viruses for multiplication.The diseases caused by gemini viruses include yellow mosaic virus of dolichos, mung bean, soybean etc, yellow vein mosaic of bhendi, leaf curl of tomato, tobacco , eggplant etc., and mosaic of cassava [56]. Soo far recorded deaths of tomato plants are mainly due to leaf curl diseases, the production of the plants is less than $10 \%$ and loss of the plant is nearly $90 \%$. As the name indicates curling of leaves, stunted growth deformed leaves are the associated symptoms of this disease [57]. The plant isolates are collected from symptomatic plants showing all the symptoms . The infected leaves are separated from the plants. DNA from the selected samples was isolated using CTAB method by Rojas and co workers 2005 [58]. Three primer pairs were used, these primers identify TOLCV virus from tomato leaves. PCR was carried out using these primers and the PCR product was analyzed through gel electrophoresis, later DNA sequencing was carried out chain termination method by sanger and co-workers. Different online tools were used to analyze the TOLCv virus and other viruses belonging to begomovirus family. TOLCV gene sequence was analysed using BLAST N and BLAST P to understand their homology. Also, the coat protein sequence of this virus was translated into protein sequence using the tool ExPASy (Expert Protein Analysis System) which is used in bioinformatics [59]. Multiple Sequence Alignment was carried out between TOLCv virus and some other viruses belonging to the same family, where sequences are retrieved from NCBI database. This MSA is carried out using Clustal W software. The sequences obtained from MSA interprets the homology and later phylogenetic analysis was carried out. The similarity between different viruses is investigated using MSA tool, there are several viruses similar to that ofTOLCv where in which TOLCV is almost similar to TYLCV (Yellow tomato leaf curl virus ) having 90-99\% sequence identity. Also with the help of NCBI, the coat protein sequence was allotted with the accession number of KC 253231 [60]. To understand computational phylogenetics MEGA (Molecular Evolutionary Genetic Analysis) version 4 was used. The phylogenetic trees were developed using Unweighted Pair Group Method of Arithmetic Averages , Maximum Parsimony and Minimum Evolution 
methods. Phylogenetic trees were generated using MSA analysis with the help of Clustal W software. In general these viruses share similarity with other viruses in MSA was seen in the phylogenetic tree [61].

Also BLAST was performed between the sequences of different viruses belonging to Gemini viridae. The similarity between the nucleotide sequences of TOLCV New Delhi virus was compared with other leaf curl viruses. Highly similar sequences are selected to better understand the genomics of the virus. The comparison between the important sequences was possible usinf BLAST tool. This review helps us to understand the ToLCV through insilico analysis and proper diagnosis and development of new methods for antiviral strategy utilizing the genomics of the causative agent i.e., ToLCV.

\section{Genetic Engineering for ToLCV:}

As known Tomato is a very important horticultural crop with a global production on 50 million hectares was however susceptible to wide range of pathogens. Mostly tomatoes are susceptible to leaf curl disease. Multiple approaches were developed previously to reduce the leaf curl virus disease and against other viruses. But the ability of the viruses to gain resistance agisnt different techniques stood as a challenge to eradicate viruses in crops [63]. Clustered regularly interspaced short palindromic repeats and associated proteins systems are innovative and rapidly acceptable novel method to engineer viral resistance. The CRISPR Cas system is known to provide good immunity response against phages.

Here we reviewed that the CRISPR Cas 9 system can target ToLCV New Delhi virus genome in tomato resulting in the interference of the virus [64].

Genetic Engineering of CRISPR Cas 9 system was successfully done in tomato crop to target ToLCV virus. This CRISPR Cas 9 mainly targets the Coat protein of the TOLCV efficiently and provides interference to tomato plants upot several generations. It was observed that CRISPR Cas (effects the REP (Replication Associate Protein) protein, but not very effective compared to coat protein [65]. Here seedlings were groen upto 30 days and these 30 days old plants were allowed to grow for few days for agroinfiltration by vector. The agrobacterium infiltration strains containing dangerous ToLCV new delhi strains was inoculated into these selected seedlings and were allowed to grow for few days along with control planst without any inoculation. 
Total RNA was extracted from the infiltrated plants using RNA easy plant mini kit . Later RNA was reverse transcribed using cDNA synthesis kit. Later the levels of rgsCaM (Regulator of Gene Silencing Calmodulin" $(\mathrm{rgsCaM})$ was observed which is naturally present in the plant and also inhibits the virus infection [66].

Inducible CRISPR Cas 9 vectors were constructed using Cas9 driven by $\mathrm{rgsCaM}$ promotor and sg rna by At U6 promotor. SgRNAs were amplified by the At U6 promotor, cut and ligation reactions were performed. The ligated samples were transferred into Ecoli and white colonies were selected and observed for the results [67].

CRISPR Cas 9 system was designed in which Cas 9 was driven by rgsCaM promotor. RT PCR results provided less presence of virus. Few sgRNA infiltrated samples showed lower presence of virus. It could be because expressions of at least one of the crisp-cas 9 construction plants sent by infiltration. We use the same order as Ali et al. To design sgRNAs. Our results are almost Approval of their report, while they report more reduction In the accumulation of viruses in sgRNA infiltration . But the novelty of our experiments is running cas 9 nuclease by promoters that can be induced to activate their activities if the virus occurs infection. Even though the CAS9 promoter has changed, data shows Endonuclease Cas9 is active catalytic

Which is a step forward to use promoters that can be induced In activating the Nuclease CAS9. Our results show that using Promoters that can be induced to activate endonuclease cas9 will Reduce Target Problems in the Crispr-Cast9 Edit Projects due to CAS9 activation for a short time and will have a significant contribution to crispr-cas9genome editing process [68]. Taking into consideration the global economic impact of viral infections In plants, it's no surprise that the more resources dedicated to breeding new plant varieties to compensate resistant alleles that are limited. Compared with current research, real results in our review are promoter efficient that can be induced in activating cas9 Protein. Our results show that using promoters that can be induced To activate Endonuclease CAS9 is possible and CAS9 is active, which is very specific and different from the Stable CRISPR / CAS9 system [69].

\section{Prospects:}

Among all the viral disease in tomato the major one is Tomato leaf curl; virus New Delhi strain which is very virulent and leads to reduced growth in the plants. There are several conventional methods to manage the disease but are not very effective and up to the mark. 
In our review we have concentrated on different methodologies associated with the leaf curl virus and tomato [70].

The biotechnology of the through LAMP and PCR technology help us to identify the disease earlier so that the damage could be reduced. Before leaf drooping, drying and stunted growth the incidence of the disease is easily known by properly understanding its biotechnology. The presence of the virus is known in the earlier stages is quiet helpful so that the plant can be saved from maximum losses [71].

Also understanding the genomics of the virus is very much important as a disease control strategy. Each and every gene is given an accession ID and number so that particular sequence can be clearly identified. The detection and confirmation of the virus is possible through ELISA test. Also, the intensity of the virus is detected using PCR technique. The genomic sequencing is a very convenient and a useful method to know the proper sequence of the viral genome and very much helpful in comparison of sequences [72].

The sequence identity to the original database is confirmed by BLAST by checking the hit list and also the sequences can be compared with each other using Multiple Sequence Alignment protocol. The similar sequences can be understood using MSA and ultimately the phylogenetic tree can be constructed. This tree draws similar sequences on the same branches and separates the sequences depending upon their similarity. The tree can be properly visualized using a tree explorer.

Along with these the genetic engineering methods are to employed to reduce or eradicate the effect of viruses on plants, in our case Tomato leaf curl virus can be completed reduced to zero with the help of CRISPR CAS 9 technique where the virulence region of the virus is removed and cloned in a particular host, when incorporated in the plant system provided a super resistance against TyLCV not only to that particular plant but up to fewer generations later. It was proven that there us lesser or no incidence of virus in the plants that were developed using CRISPR CAS 9 method.

It is therefore very well understood that tomato which was a very important horticultural crop with many nutritional advantages and comfortable crops to grow anywhere is facing a serious problem due to TyLCV New Delhi virus which is affecting the entire crop growth and development ultimately leading to the death of the entire crop. So, several methods were discussed in our review in a point of view to reduce the effect this deadly virus on the crop growth by understanding $t$ the biotechnology and genomics of the virus and possible genetic 
engineering to reduce or completely eradicate the virus in the crop using an emerging and wonderful technique like CRISPR CAS 9.

\section{REFERENCES:}

1. Robertson Larry, Joanne Labate. Genetic Resources of Tomato (Lycopersicon esculentum Mill.) and Wild RelativesJanuary 2006DOI:10.1201/b10744-3 In book: Genetic Improvement of Solanaceous Crops Volume 2 (pp.25-75).

2. Rick CM and Holle M (1990) Andean Lycopersicon esculentum var.cerasiformi: Genetic variation and its evolutionary significance. Econ Bot 44: 69-78.

3. Kaushik P, Dhaliwal MS. Diallel analysis for morphological and biochemical traits in tomato cultivated under the influence of tomato leaf curl virus. Agronomy. 2018;8(8):153.

4. CS A, Kaushik P, others. Diallel analysis of chilli pepper (Capsicum annuum L.) genotypes for morphological and fruit biochemical traits. Plants. 2020;9(1):1.

5. Vijeth S, Dhaliwal M, Jindal S, Garg N, Kaushik P, Sharma A. Diallel analysis of elite tomato lines comprising leaf curl virus resistance genes. Applied Ecology and Environmental Research. 2019;17(3):6457-71.

6. Kaushik P, Plazas M, Prohens J, Vilanova S, Gramazio P. Diallel genetic analysis for multiple traits in eggplant and assessment of genetic distances for predicting hybrids performance. Plos One. 2018;13(6):e0199943.

7. KAUSHIK P. Tomato Leaf Curl Virus Resistance in Tomato (Solanum lycopersicum) Hybrids Grown in the Rainy Season under Punjab Conditions. Arch Insect Biochem Physiol. 58:216-25.

8. Vijeth S, Sreelathakumary I, Aiswarya CS, Kaushik P. Screening Of Popular Indian Chili Pepper (Capsicum annuum L.) Genotypes Against the Chili leaf curl virus Disease. Plant Pathology Journal. 2020;19(2):121-31.

9. Kaushik P, Dhaliwal MS. Diallel analysis for morphological and biochemical traits in tomato cultivated under the influence of tomato leaf curl virus. Agronomy. 2018;8(8):153.

10. Kaushik P, Dhaliwal MS, Jindal SK, Srivastava A, Tyagi V, Brar NS, et al. Heterosis and leaf curl virus resistance in rainy season tomato under North Indian conditions. African Journal of Agricultural Research. 2015;10(29):2763-72. 
11. Kaushik P. Line\$times\$ Tester analysis for morphological and fruit biochemical traits in eggplant (Solanum melongena L.) using wild relatives as testers. Agronomy. 2019;9(4):185.

12. Singh B, Kaul S, Kumar D and Kumar V (2010) Combining ability for yield and its contributing characters in tomato. Indian J Hort 67: 50-55.

13. Mayee C D, Kanwar J S and Nandpuri K S (1974) The comparative performance of different genotypes of tomato vis-a-vis leaf curl and mosaic. Punjab Agric Univ J Res 11: $362-364$.

14. Green S K and Kalloo G (1994) Leaf curl and yellowing viruses of pepper and tomato: An overview. AVRDC Tech.Bull.No21.

15. Chakraborty S, Pandey P K, Banerjee M K, Kalloo G and Fauquet C M (2003) Tomato leaf curl Gujarat virus, a new begomovirus species causing a severe leaf curl disease of tomato in Varanasi, India. Phytopathology 93:1485-1495.

16. Sharma I, Dhaliwal IK, Bijalwan P, Yadav VK, Kaushik P. A Brief Perspective on Lost Traditional Grains and Food Habits of Indians. Int J Curr Microbiol App Sci. 2020;9(12):2295-305.

17. Malhi GS, Kaur M, Kaushik P. Impact of climate change on agriculture and its mitigation strategies: A review. Sustainability. 2021;13(3):1318.

18. Brar NS, Saini DK, Kaushik P, Chauhan J, Kamboj NK. Directing for higher seed production in vegetables. Agronomy-Climate Change \& Food Security. 2020;55.

19. Kaushik P. Precision Vegetable Farming Technologies: An Update. 2021;

20. Saini I, Kaushik P, Saini BL. Role of Indian Women in Conservation of Biodiversity. Int J Curr Microbiol App Sci. 2019;8(4):63-8.

21. Priyanka V, Kumar R, Dhaliwal I, Kaushik P. Germplasm Conservation: Instrumental in Agricultural Biodiversity-A Review. Sustainability. 2021;13(12):6743.

22. Singh H, Sethi S, Kaushik P, Fulford A. Grafting vegetables for mitigating environmental stresses under climate change: a review. Journal of Water and Climate Change. 2020;11(4):1784-97.

23. Brar NS, Kumar T, Kaushik P. Integration of technologies under climate change for profitability in vegetable cultivation: an outlook. 2020;

24. Kumar A, Kumar P, Kumar A, others. Study of Various Development Media for Standardization of Immature Embryo Culture in Capsicum annuum L. Biosciences. $2013 ; 237$. 
25. Fabre, F., Rousseau, E., Mailleret, L. and Moury, B. (2012) Durable strategies to deploy plant resistance in agricultural landscapes.New Phytol.193, 1064-1075

26. Choi, B., Kwon, S.J., Kim, M.H., Choe, S., Kwak, H.R., Kim, M.K., Jung, C. et al. (2019) A plant virus-based vector system for gene function studies in pepper. Plant Physiol. 181, 867-880.

27. Kil, E.J., Kim, S., Lee, Y.J., Byun, H.S., Park, J., Seo, H., Kim, C.S. et al. (2016) Tomato yellow leaf curl virus (TYLCV-IL): a seed-transmissible geminivirus in tomatoes. Sci. Rep. 6, 19013.

28. Basak J. Tomato yellow leaf curl virus: A serious threat to tomato plants world. $\mathbf{J}$ Plant Pathol Microbiology: OMICS Int. 2016;3:1000346.

29. Lefeuvre, P., et al. The spread of tomato yellow leaf curl virus from the Middle East to the world. PLOS Pathogens. 2010;6(10): e1001164. doi:10.1371/journal.ppat.1000975.

30. Verlaan MG, Hutton SF, Ibrahem RM, Kormelink R, Visser RGF, Scott JW, Edwards JD, Bai Y, McDowell JM. The tomato yellow leaf curl virus resistance genes Ty-1 and Ty-3 are allelic and code for DFDGD-class RNA-dependent RNA polymerases. PLoS Genet. 2013;9(3):e1003399. doi:10.1371/ journal.pgen.1003399

31. Avidov, H.Z. (1944). Tobacco Whitefly in Israel (pp. 1-33). Tel Aviv: Hassadeh (in Hebrew)

32. Czosnek, H., Ber, R., Antignus, Y., Cohen, S., Navot, N., \& Zamir, D. (1988). Isolation of tomato yellow leaf curl virus, a geminivirus. Phytopathology, 78, 508512. doi:10.1094/Phyto-78-508

33. Fauquet, C.M., Briddon, R.W., Brown, J.K., Moriones, E., Stanley, J., Zerbini, M., \& Zhou, X. (2008). Geminivirus strain demarcation and nomenclature. Archives of Virology, 153, 783-821. doi:10.1007/s00705-008-0037-6

34. Kings, A.M.Q., Adams, M.J., Carstens, E.B., \& Lefkowitz, E.J. (2011). Virus taxonomy: Ninth report of the international committee on taxonomy of viruses. London: Elsevier.

35. Czosnek, H., \& Laterrot, H. (1997). A worldwide survey of Tomato yellow leaf curl viruses. Archives of Virology, 142, 1391-1406. doi:10.1007/s007050050168 Czosnek, H., Navot, N., \& Laterrot, H. (1990

36. Makkouk, K.M. (1978). A study on tomato viruses in the Jordan Valley with special emphasis on Tomato yellow leaf curl. Plant Disease Reporter, 62, 259-262. 
37. Makkouk, K.M., Shehab, S., \& Majdalani, S.E. (1979). Tomato yellow leaf curl: Incidence, yield losses and trans1mission in Lebanon. Journal of Phytopathology, 96, 263- 267. doi:10.1111/j.1439-0434.1979.tb01648.x

38. Rojas, M.R., Kon, T., Natwick, E.T., Polston, J.E., Akad, F., \& Gilbertson, R.L. (2007). First report of tomato yellow leaf curl virus associated with tomato yellow leaf curl disease in California. Plant Disease, 91, 1056. doi:10.1094/PDIS191-8$1056 \mathrm{~A}$

39. Melzer, M.J., Ogata, D.Y., Fukuda, S.K., Shimabuku, R., Borth, W.B., Sether, D.M., \& Hu, J.S. (2010). First report of Tomato yellow leaf curl virus in Hawaii. Plant Disease, 94, 641. doi:10.1094/PDIS-94-5-0641B

40. Zhang, H., Gong, H., \& Zhou, X. (2009). Molecular char1 acterization and pathogenicity of Tomato yellow leaf curl virus in China. Virus Genes, 39, 249-255. doi:10.1007/ s11262-009-0384-8

41. Chinnaraja, C., Ramkissoon, A., Ramsubhag, A., \& Jayaraj, J. (2016). First report of Tomato yellow leaf curl virus infecting tomatoes in Trinidad. Plant Disease, 100, 1958. doi:10.1094/PDIS-04-16-0446-PDN

42. Lapidot, M. (2007). Screening for TYLCV-resistant plants using whitefly-mediated inoculation. In: H. Czosnek (Ed.), Tomato yellow leaf curl virus disease: management, molecular biology, breeding for resistance (pp. 329-342). Dordrecht, The Netherlands: Springer.

43. Supradip Saha, Nirmal K Hedau, Vinay Mahajan, Gyanendra Singh, Hari S Gupta, Anita Gahalain. Textural, nutritional and functional attributes in tomato genotypes for breeding better quality varieties, irst published: 04 November 2005 https://doi.org/10.1002/jsfa.3802

44. Czosnek, H., Ghanim, M., 2012. Back to basics: are begomoviruses whitefly pathogens? Journal of Integrative Agriculture 11, 225-234

45. Arooj, S., Iftekhar, Y., Mubeen, M., Ullah, M.I., Sajid, A., Ali, S., Shakeel, Q., Aatif, M., Raza, W., Noorka, I.R., 2019. Effect of environmental factors on biochemical properties of tomato leaf curl virus infected leaves of tomato. Pakistan Journal of Phytopathology 31, 105-111.

46. Iftikhar, Y., Arooj, S., Kamran, M., Ullah, M.I., Mubeen, M., Shakeel, Q., Zeerak, N., Bilqees, I., 2020. Management of tomato leaf curl virus through non-chemicals in relation to environmental factors. Pakistan Journal of Phytopathology 29, 41-46. 
47. UmarNaim Abdullahi, RochmanWan Taib, WanRohani Saleh, Ahmadu Muazu, Anas Aliyu, Sani Baig Atif, Loop-mediated isothermal amplification (LAMP), an innovation in gene amplification: bridging the gap in molecular diagnostics; a re1view, Indian J. Sci. Technol. 8 (2015) 1-12, https://doi.org/10.17485/ijst/2015/ v8i17/55767

48. Malhi GS, Kaur M, Kaushik P, Alyemeni MN, Alsahli AA, Ahmad P. Arbuscular mycorrhiza in combating abiotic stresses in vegetables: An eco-friendly approach. Saudi Journal of Biological Sciences. 2021;28(2):1465.

49. Sinha S, Sandhu K, Bisht N, Naliwal T, Saini I, Kaushik P. Ascertaining the paradigm of secondary metabolism enhancement through gene level modification in therapeutic plants. Journal of Young Pharmacists. 2019;11(4):337.

50. Yadav V, Jha R, Kaushik P, others. Biochemical composition of potato biowaste of popular North Indian cultivars. Indian Journal of Biochemistry and Biophysics (IJBB). 2021;58(1):100-4.

51. Yadav VK, Singh R, Jha RK, Kaushik P, others. Biochemical variability of eggplant peel among Indian cultivars. Indian Journal of Biochemistry and Biophysics (IJBB). 2020;57(5):634-7.

52. Sharma M, Kaushik P. Breeding for Root-Knot Nematode Resistance in Eggplant: Progress and Prospects. 2021;

53. Kaushik P. Characterization of Cultivated Eggplant and its Wild Relatives Based on Important Fruit Biochemical Traits. Pakistan Journal of Biological Sciences: PJBS. 2020;23(9):1220-6.

54. Kaushik P, Kumar P, Kumar S, others. Enhancement of chlorogenic content of the eggplant fruit with eggplant hydroxycinnamoyl CoA-quinate transferase gene via novel agroinfiltration protocol. Pharmacognosy Magazine. 2020;16(5):450.

55. Sunilkumar P MK, Vijeth, S, Rathod, V, Kaushik. Genetic Associations Analysis in Tomato (Solanum lycopersicum L.) Involving Improved Germplasm Lines for Agronomic and Yield Contributing Traits. IntJCurrMicrobiolAppSci. 2019;8(10):2688-702. 
56. Sunilkumar M. Genetic divergence in exotic tomato (Solanum lycopersicum L.) genotypes cultivated in southern India. Journal of Pharmacognosy and Phytochemistry. 2019;8(4):710-2.

57. Saini I, Chauhan J, Kaushik P. Medicinal value of domiciliary ornamental plants of the Asteraceae family. Journal of Young Pharmacists. 2020;12(1):3.

58. Kaushik P, Saini DK. Silicon as a vegetable crops modulator-A review. Plants. 2019;8(6):148.

59. Kaushik P. Standardisation of an Agroinfiltration Protocol for Eggplant Fruits and Proving its Usefulness by Over-expressing the SmHQT Gene. 2019;

60. M. Taniuchi, J.J. Verweij, Z. Noor, S.U. Sobuz, L. Lieshout, W.A. Petri Jr., R. Haque, E.R. Houpt High throughput multiplex PCR and probe-based detection with Luminex beads for seven intestinal parasites Am. J. Trop. Med. Hyg., 84 (2011), pp. 332-337

61. P. Satya, S. Mitra, D.P. Ray, B.S. Mahapatra, M. Karan, S. Jana, A.K. Sharma Rapid and inexpensive $\mathrm{NaOH}$ based direct PCR for amplification of nuclear and organelle DNA from ramie (Boehmerianivea), a bast fibre crop containing complex polysaccharides Ind Crop Prod., 50 (2013), pp. 532-536

62. B.P.V. Martínez-Culebras, I. Font, C. Jordá A rapid PCR method to discriminate between Tomato yellow leaf curl virus isolatesAnn. Appl. Biol., 139 (2001), pp. 251 257

63. Eui-Joon Kil, KimSunhoo Lee, Ye-Ji Byun, HeeSeong Park, Jungho Seo, Haneul Kim, Chang-Seok Shim, Jae-Kyoung Lee, JungHwan Kim, Ji-Kwang Lee, Kyeong-Yeoll Choi, Hong-Soo Lee, Sukchan Tomato yellow leaf curl virus (TYLCV-IL): A seed-transmissible geminivirus in tomatoes Sci. Rep., 6 (2016), Article 19013, 10.1038/srep19013

64. Al-Ali, E.H., Al-Hashash, H.K., Ben-Hejji, A.H., Al-Shayjji, N. and Al-Aqeel, H.A. 2015. First complete genomic characterization and phylogeny of a new recombinant of tomato yellow leaf curl virus (genus Begomovirus, family Geminiviridae) from Kuwait. Archives of Virology 160(7): 1823-1826. doi: 10.1007/s00705-015-2427-x.

65. Krenz, B., Thompson, J.R., McLane, H.L., Fuchs, M. and Perry, K.L. 2014. Grapevine red blotch-associated virus Is Widespread in the United States. Phytopathology Journal 104(11): 1232-40. doi: 10.1094/PHYTO-02-14-0053-R.

66. Doyle, J.J. and Doyle, J.L. 1987. A rapid DNA isolation procedure from small quantities of fresh leaf tissues. Phytochemical Bulletin 19: 11-15 
67. Naqvi, A.R., Sarwat, M., Pradhan, B., Choudhury, N.R., Haq, Q.M. and Mukherjee, S.K. 2011. Differential expression analyses of host genes involved in systemic infection of Tomato leaf curl New Delhi virus (ToLCNDV). Vir Research 160: 395399. doi: 10.1016/j.virusres.2011.05.002

68. Fiallo-Olivé, E., Zerbini, F.M. and Navas-Castillo, J. 2015. Complete nucleotide sequences of two new begomoviruses infecting the wild malvaceous plant Melochia sp. in Brazil. Archives of Virology 160(12): 3161- 3164. doi: 10.1007/s00705-0152619-4.

69. Rojas, A., Kvarnheden, A., Marcenaro, D. and Valkonen, J.P. 2005. Sequence characterization of tomato leaf curl Sinaloa virus and tomato severe leaf curl virus: Phylogeny of New World begomoviruses and detection of recombination. Archives of Virology 150(7): 1281-1299

70. Zhang, H., Gong, H. and Zhou, X. 2009. Molecular characterization and pathogenicity of tomato yellow leaf curl virus in China. Vir Genes 39(2): 249-255. doi:10.1007/ s11262-009-0384-8

71. Basak J. Tomato yellow leaf curl virus: A serious threat to tomato plants world. J Plant Pathol Microbiology: OMICS Int. 2016;3:1000346.

72. Soppe JA, Lebbink RJ. Antiviral goes viral: harnessing CRISPR/ Cas9 to combat viruses in humans. Trends Microbiol. 2017;25 (10):833-850.

doi:10.1016/j.tim.2017.04.005 